\title{
Phase III randomized trial of preoperative concurrent chemoradiotherapy versus preoperative radiotherapy for patients with locally advanced head and neck squamous cell carcinoma
}

\author{
Junlin $\mathrm{Yi}^{1}$, Xiaodong Huang ${ }^{1}$, Zhengang $\mathrm{Xu}^{2}{ }^{2}$, Shaoyan Liu ${ }^{2}$, Xiaolei Wang ${ }^{2}$, Xiaohui \\ $\mathrm{He}^{3}$, Dehong $\mathrm{Luo}^{4}$, Jingwei Luo ${ }^{1}$, Jianping Xiao ${ }^{1}$, Shiping Zhang ${ }^{1}$, Kai Wang ${ }^{1}$, \\ Yuan Qu ${ }^{1}$, Yuan Tang ${ }^{1}$, Weixin Liu ${ }^{1}$, Guozhen $X \mathbf{u}^{1}$, Li Gao ${ }^{1}$ and Dian Wang ${ }^{5}$ \\ ${ }^{1}$ Department of Radiation Oncology, National Cancer Center/Cancer Hospital, Chinese Academy of Medical Sciences and \\ Peking Union Medical College, Beijing, P. R. China \\ ${ }^{2}$ Department of Surgery, National Cancer Center/Cancer Hospital, Chinese Academy of Medical Sciences and Peking Union \\ Medical College, Beijing, P. R. China \\ ${ }^{3}$ Department of Medical Oncology, National Cancer Center/Cancer Hospital, Chinese Academy of Medical Sciences and \\ Peking Union Medical College, Beijing, P. R. China \\ ${ }^{4}$ Department of Diagnostic Radiology, National Cancer Center/Cancer Hospital, Chinese Academy of Medical Sciences and \\ Peking Union Medical College, Beijing, P. R. China \\ ${ }^{5}$ Department of Radiation Oncology, Rush University Medical Center, Chicago, USA \\ Correspondence to: Li Gao, email: li_gao2008@outlook.com
}

Keywords: head and neck squamous cell carcinoma; preoperative radiotherapy; concurrent chemoradiotherapy; multimodality treatment; organ function preservation

Received: November 22, $2016 \quad$ Accepted: January 11, $2017 \quad$ Published: February 05, 2017

Copyright: Yi et al. This is an open-access article distributed under the terms of the Creative Commons Attribution License 3.0 (CC BY 3.0), which permits unrestricted use, distribution, and reproduction in any medium, provided the original author and source are credited.

\section{ABSTRACT}

Purpose: To determine the role of preoperative concurrent chemoradiotherapy in the treatment of locally advanced head and neck squamous cell carcinoma (HNSCC).

Methods: A total of 222 patients with stage III/IVA-B HNSCC were randomly assigned to receive preoperative concurrent chemoradiotherapy (Pre-S CRT, weekly cisplatin $30 \mathrm{mg} / \mathrm{m}^{2}$ ) or preoperative radiotherapy alone (Pre-S RT). Survival analysis was estimated by the Kaplan-Meier method and compared by the log-rank test.

Results: With a medial follow-up of 59 month, the 5-year overall survival (OS), progression-free survival (PFS), distant metastasis-free survival (DMFS) of Pre-S CRT $v$ Pre-S RT group were 53.8\% v 39.0\% (hazard ratio [HR], 0.74, 95\% CI, 0.50 to $1.10, P=0.13), 53.2 \%$ v 38.7\%, (HR, 0.69, 95\% CI, 0.47 to $1.01, P=0.06)$, and $80.4 \% v 68.1 \%(H R, 0.53,95 \% C I, 0.28$ to $0.98, P=0.04)$, respectively. In patients with larynx-hypopharynx primaries, the 5-year OS, PFS and DMFS of Pre-S CRT v Pre-S RT were 62.7\% v 38.8\% (HR, 0.59, 95\% CI 0.35 to $1.02, P=0.054), 63.1 \% v$ 39.9\% (HR, 0.52; 95\% CI 0.30 to $0.89, P=0.03)$ and $86.2 \%$ v $63.3 \%(H R, 0.35,95 \%$ CI 0.15 to $0.82, P=0.01)$, respectively.

Conclusion: The addition of weekly cisplatin concurrent to preoperative RT does not improve OS, but improve DMFS in locally advanced HNSCC. However, in a subset of patients with the larynx-hypopharynx primaries, preoperative chemoradiotherapy has significantly improved PFS and DMFS, and has also provided a borderline benefit in OS in comparison with preoperative radiotherapy alone. 


\section{INTRODUCTION}

Although preoperative radiotherapy (RT) was reportedly associated with more toxicity than postoperative RT by the results of RTOG multicenter phase 3 trial 7303 [1-3], preoperative RT strategy has been successfully utilized with acceptable toxicity profile in our cancer center [4-10]. We have routinely prescribed preoperative RT (50 Gy in 25 fractions) to locally advanced HNSCC, followed by either resection of non-responding tumor (defined as less than $80 \%$ shrinking) or additional RT boost to other responding tumors. Benefits of this preoperative treatment strategy including organ-function preservation and avoiding surgical related morbidities such as poor quality of life outcomes (functional and cosmetic) for patients who had good response to preoperative radiotherapy and could cured by radical radiotherapy; and might facilitate resection for tumors that does not respond to preoperative RT and improved outcomes of these patients. Toxicities associated with preoperative radiotherapy were reported to be not higher than those associated with postoperative radiotherapy in our experience.

This phase 3 study was developed in early 2000 when results of several phase 2 studies suggested that preoperative concurrent chemoradiotherapy (CRT) resulted in excellent treatment outcome with pathological complete response rate of $35 \%-61 \%$ and 5 -years overall survival rate of $70 \%-81.5 \%$ in patients with nonnasopharyngeal HNSCC [11-18]. A subsequent metaanalyses data showed that CRT can improve the overall survival with a $6.5 \%$ to $8 \%$ absolutely benefit at 5 years, compared with radiotherapy alone [19]. Accumulated data including results of several phase 3 trials and updated meta-analysis have indeed demonstrated survival benefits of definitive CRT over definitive RT alone [20,21]. Given the established experience of preoperative radiotherapy of locally advanced non-nasopharynx HNSCC in our institution, we launched this phase 3 trial to investigate whether or not the preoperative concurrent CRT is superior to preoperative RT in the treatment of locally advanced HNSCC. For patients with significant response $(80 \%$ or more shrinking of primary tumor) to initial 5-week RT or 5-week CRT, we chose to proceed with definitive RT versus CRT in this protocol.

\section{RESULTS}

\section{Clinical features}

From September 2002 to May 2012, a total of 240 patients were enrolled to this study, with 116 patients assigned to the Pre-S CRT group and 124 patients to the Pre-S RT group. In the Pre-S CRT group, 2 patients withdraw from information consent, 4 patients did not finish protocol treatment because of financial reason, 6 patients lost follow-up immediately after treatment. In the Pre-S RT group, 2 patients did not finish protocol treatment because of financial reason, 4 patients lost follow-up immediately after treatment. A total Of 222 patients were evaluable, 104 patients in the Pre-S CRT group and 118 patients in the Pre-S RT group. The clinical characteristics of these two groups were summarized in the Table 1.

\section{Response to preoperative treatment}

In the Pre-S RT group, 70.3\% (83/118) patients were responders while $29.7 \%$ (35/118) patients were non-responders. Similarly, in the Pre-CRT group, $64.4 \%$ (67/104) patients were responders while $35.6 \%$ (37/104) were non-responders $(P=0.35)$. For the non-responders who underwent resection of primary tumors, the pathological complete responses rates were $42.9 \%(15 / 35)$ in the Pre-S RT versus $27.0 \%$ (10/37) in the Pre-S CRT group $(P=0.16)$.

\section{Clinical outcomes}

With a medial follow-up of 59 month in a range of 7 to 122 months, the 5-year estimated LRC, OS, progression free survival (PFS), and distant metastasis free survival (DMFS) for the entire group were $66.4 \%, 46.2 \%, 45.6 \%$ and $73.9 \%$, respectively. The 5-year DMFS and PFS of the Pre-S CRT $v$ Pre-S RT groups were $80.4 \% v 68.1 \%$ (HR, $0.53,95 \% \mathrm{CI}, 0.28$ to $0.98, P=0.04)$ and $53.2 \% v 38.7 \%$ (HR, $0.69,95 \% \mathrm{CI}, 0.47$ to $1.01, P=0.06$ ), respectively. However, there was no difference in the 5-year OS and LRC rates between the Pre-S CRT and Pre-S RT, 53.8\%v $39.0 \%$, (HR, $0.74,95 \%$ CI, 0.50 to $1.10, P=0.13$ ) for OS and $70.1 \% v 62.4 \%$ (HR, $0.83,95 \% \mathrm{CI}, 0.50$ to $1.38, P=$ 0.47 ) for LRC, respectively (Figure 2).

\section{Patterns of failure}

One hundred and eight patients developed disease recurrence including failures in primary sites, regional nodal and distant metastasis. Of them were 44 in the Pre-S CRT and 64 in the Pre-S RT group. Failures in primary site or regional neck or distant metastasis were not different between these two groups as shown in Table 2.

\section{Treatment-related toxicities}

The main hematology toxicities observed in this trial were leucopenia, anemia, and thrombocytopenia. There was a significant difference in grade $3+$ hematology 
Table 1: Patient characteristics in Pre-S CRT and Pre-S RT groups

\begin{tabular}{|c|c|c|c|c|c|}
\hline \multirow{2}{*}{ Characteristics } & \multicolumn{2}{|c|}{ Pre-S CRT $(n=104)$} & \multicolumn{2}{|c|}{ Pre-S RT $(n=118)$} & \multirow{2}{*}{$P$} \\
\hline & $n$ & $\%$ & $n$ & $\%$ & \\
\hline $\begin{array}{l}\text { Gender } \\
\text { Male } \\
\text { Female } \\
\end{array}$ & $\begin{array}{l}85 \\
19 \\
\end{array}$ & $\begin{array}{l}81.7 \\
18.3 \\
\end{array}$ & $105 \quad 13$ & $\begin{array}{l}82.2 \\
17.8 \\
\end{array}$ & 0.13 \\
\hline Medial age (years) & & 55 & 55 & & \\
\hline $\begin{array}{l}\text { Primary site } \\
\text { Oral cavity } \\
\text { oropharynx } \\
\text { Hypopharynx/ Larynx }\end{array}$ & $\begin{array}{l}14 \\
30 \\
60 \\
\end{array}$ & $\begin{array}{l}13.5 \\
28.8 \\
57.7\end{array}$ & $\begin{array}{l}14 \\
36 \\
68 \\
\end{array}$ & $\begin{array}{l}11.9 \\
30.5 \\
57.6\end{array}$ & 0.52 \\
\hline $\begin{array}{l}\text { T stage } \\
\text { T1 } \\
\text { T2 } \\
\text { T3 } \\
\text { T4a } \\
\text { T4b } \\
\end{array}$ & $\begin{array}{r}6 \\
18 \\
22 \\
51 \\
7 \\
\end{array}$ & $\begin{array}{r}5.8 \\
17.3 \\
21.2 \\
49.0 \\
6.7 \\
\end{array}$ & $\begin{array}{r}6 \\
25 \\
43 \\
36 \\
8 \\
\end{array}$ & $\begin{array}{c}5.1 \\
21.2 \\
36.4 \\
30.5 \\
6.8 \\
\end{array}$ & 0.05 \\
\hline $\begin{array}{l}\text { N stage } \\
\text { N0 } \\
\text { N1 } \\
\text { N2 } \\
\text { N3 } \\
\end{array}$ & $\begin{array}{r}9 \\
20 \\
62 \\
13 \\
\end{array}$ & $\begin{array}{c}8.7 \\
19.2 \\
59.6 \\
12.5 \\
\end{array}$ & $\begin{array}{l}19 \\
22 \\
60 \\
17 \\
\end{array}$ & $\begin{array}{l}16.1 \\
18.6 \\
50.9 \\
14.4 \\
\end{array}$ & 0.36 \\
\hline $\begin{array}{l}\text { Clinical group } \\
\text { III } \\
\text { IVA } \\
\text { IVB } \\
\end{array}$ & $\begin{array}{l}14 \\
70 \\
20\end{array}$ & $\begin{array}{l}13.5 \\
67.3 \\
19.2\end{array}$ & $\begin{array}{l}21 \\
73 \\
24\end{array}$ & $\begin{array}{l}17.8 \\
61.9 \\
20.3 \\
\end{array}$ & 0.62 \\
\hline $\begin{array}{l}\text { Medial } \\
\text { Chemotherapy cycle }\end{array}$ & & 5 & none & & \\
\hline $\begin{array}{l}\text { Radiotherapy technique } \\
\text { 3DCRT } \\
\text { IMRT }\end{array}$ & $\begin{array}{l}62 \\
42\end{array}$ & $\begin{array}{l}59.6 \\
40.4\end{array}$ & $\begin{array}{l}62 \\
56\end{array}$ & $\begin{array}{l}52.5 \\
47.5\end{array}$ & 0.29 \\
\hline
\end{tabular}

Pre-S RT: preoperative radiotherapy; Pre-S CRT: preoperative concurrent chemoradiotherapy; 3DCRT: three-dimensional conformal radiotherapy; IMRT: intensity-modulated radiotherapy.

Table 2: Failure pattern in the Pre-S CRT and Pre-S RT groups

\begin{tabular}{|c|c|c|c|c|c|}
\hline \multirow{3}{*}{ Failure pattern } & \multicolumn{4}{|c|}{ Treatment } & \multirow{3}{*}{$P$} \\
\hline & \multicolumn{2}{|c|}{ Pre-SCRT $(n=104)$} & \multicolumn{2}{|c|}{ Pre-S RT $(n=118)$} & \\
\hline & $n$ & $\%$ & $n$ & $\%$ & \\
\hline Primary site & 27 & 25.9 & 34 & 28.8 & 0.635 \\
\hline Regional lymph node & 10 & 9.62 & 12 & 10.2 & 0.890 \\
\hline Distant & 15 & 14.4 & 29 & 24.5 & 0.058 \\
\hline
\end{tabular}

Pre-S RT: preoperative radiotherapy; Pre-S CRT: preoperative concurrent chemoradiotherapy.

toxicities between Pre-S CRT and Pre-S RT group, 16.3\% $v 0.8 \%(P<0.001)$. The main non-hematology toxicities were mucositis, pharygalgia, xerostomia, and skin reactions. There were no significant differences in rates of the above main non-hematology toxicities between the CRT and RT groups (Table 3). The most common surgery-related complications were pharyngeal fistula, wound infection and wound healing delay. There were no significant difference between Pre-S CRT and Pre-S RT group, with pharyngeal fistula incidence of $5(5 / 37)$ and $4(4 / 35)$, wound healing delay and infection incidence of $2(2 / 37)$ and $1(1 / 35)$ in Pre-S CRT and Pre-S RT group, repectively.

\section{Subset analyses restricted to larynx-hypopharynx primaries}

Of 128 patients with larynx-hypopharynx primaries enrolled to this study, $60(57.6 \%)$ patients were in the Pre-S CRT while $68(57.7 \%)$ patients were in the Pre-S RT group. The 5-year OS of Pre-S CRT $v$ Pre-S RT group shows a trend toward a statistical difference, $62.7 \% v$ $38.8 \%$ (HR, $0.59,95 \%$ CI, 0.35 to $1.02, P=0.054$ ). The 5 -year PFS, DMFS and LRC between Pre S RT $v$ Pre S CRT were $63.1 \% v 39.9 \%$ (HR, $0.52,95 \% \mathrm{CI}, 0.30$ to $0.89, P=0.03$ ) for PFS, $86.2 \% v 63.3 \%$ (HR, $0.35,95 \%$ 
Table 3: Incidences of treatment-related toxicities in the Pre-S CRT and Pre-S RT groups

\begin{tabular}{|c|c|c|c|c|c|c|c|c|c|}
\hline \multirow{3}{*}{ Acute Toxicities } & \multicolumn{4}{|c|}{ Pre-S CRT $(n=104)$} & \multicolumn{4}{|c|}{ Pre-S RT $(n=118)$} & \multirow{3}{*}{$\boldsymbol{P}$} \\
\hline & \multicolumn{2}{|c|}{ Grade I/II } & \multicolumn{2}{|c|}{ Grade III/IV } & \multicolumn{2}{|c|}{ Grade I/II } & \multicolumn{2}{|c|}{ Grade III/IV } & \\
\hline & $n$ & $\%$ & $n$ & $\%$ & $n$ & $\%$ & $n$ & $\%$ & \\
\hline Anemia & 46 & 44.2 & 1 & 0.96 & 19 & 16.1 & 0 & 0 & $<0.001$ \\
\hline Leucopenia & 74 & 71.2 & 11 & 10.6 & 40 & 33.9 & 0 & 0 & $<0.001$ \\
\hline Thrombocytopenia & 19 & 18.3 & 5 & 4.8 & 3 & 2.55 & 1 & 0.85 & $<0.001$ \\
\hline Liver function & 3 & 2.9 & 0 & 0 & 6 & 5.1 & 0 & 0 & 0.41 \\
\hline Renal function & 5 & 4.81 & 1 & 0.96 & 2 & 1.7 & 0 & 0 & 0.23 \\
\hline Mucositis & 74 & 71.2 & 29 & 27.9 & 99 & 83.9 & 25 & 21.2 & 0.37 \\
\hline Pharyngalgia & 82 & 78.8 & 14 & 13.5 & 99 & 83.9 & 13 & 11.0 & 0.87 \\
\hline Xerostomia & 103 & 99.0 & 1 & 0.96 & 102 & 86.5 & 0 & 0 & 0.88 \\
\hline Skin reaction & 94 & 90.4 & 6 & 5.8 & 114 & 96.6 & 4 & 3.39 & 0.15 \\
\hline
\end{tabular}

Pre-S RT: preoperative radiotherapy; Pre-S CRT: preoperative concurrent chemoradiotherapy.

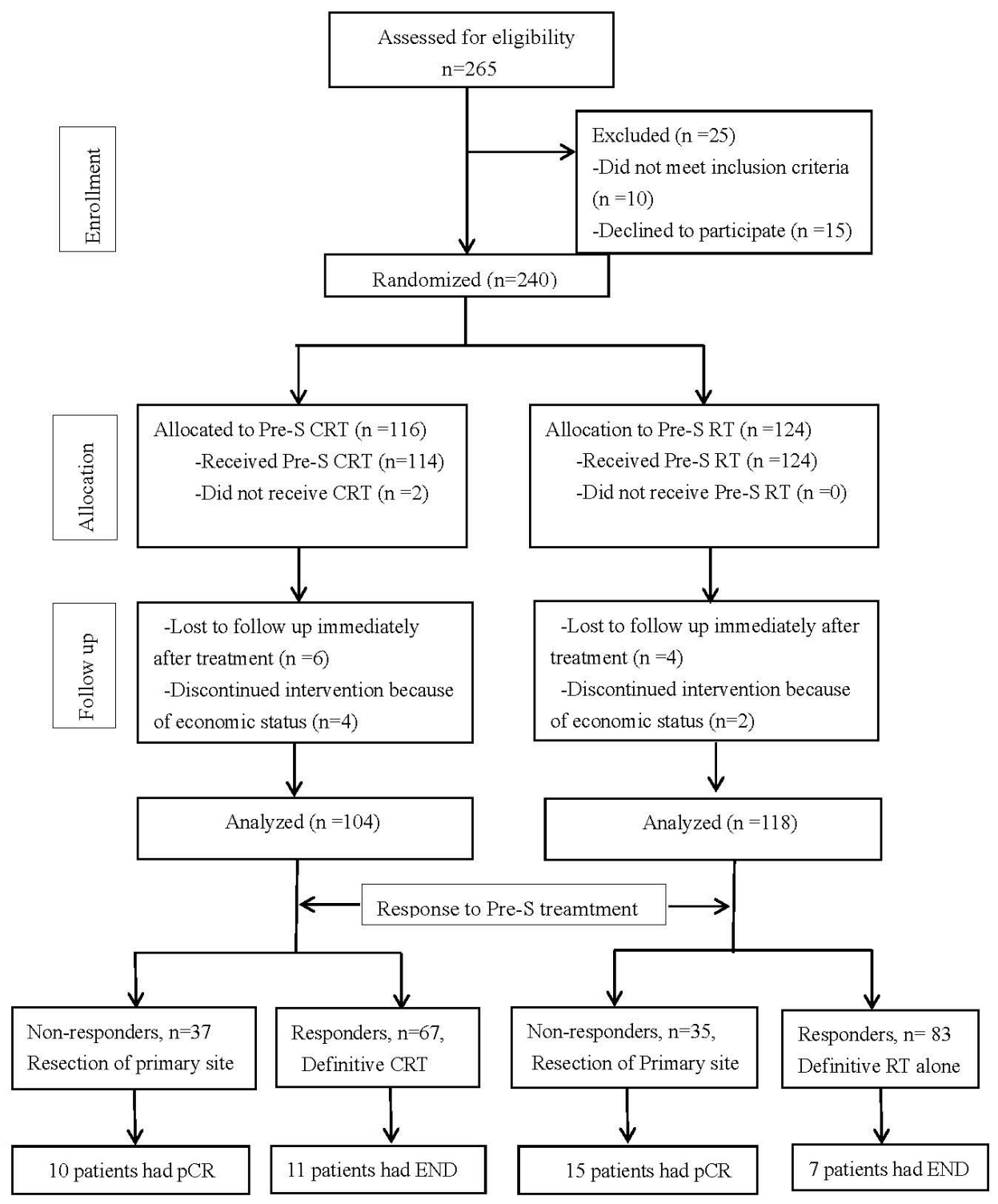

Figure 1: CONSORT diagram. 
CI, 0.15 to $0.82, P=0.01$ ) for DMFS and $81.4 \% v 69.3 \%$ (HR, $1.59,95 \% \mathrm{CI}, 0.71$ to $3.54, P=0.29$ ) for LRC. The laryngectomy-free survival in the Pre-S CRT and the Pre-S RT group were $75.5 \%$ and $64.5 \%$, (HR, $0.64,95 \%$ CI, 0.30 to $1.36, P=0.23$ ) (Figure 3 ).

\section{DISCUSSION}

To our best knowledge, this is the first phase 3 trial to compare preoperative chemoradiotherapay (CRT) and preoperative RT in the treatment of non-nasopharynx HNSCC. Results of this phase 3 trial show that the addition of weekly $30 \mathrm{mg} / \mathrm{m}^{2}$ cisplatin to preoperative radiotherapy did not enhance OS, but significantly improved 5-year DMFS, 80.4\% v 68.1\% $(P=0.04)$, and also borderline significance in PFS (53.2\% v 38.7\%, $P=0.06$ ) when compared to preoperative radiotherapy alone. In a subset of the larynx-hypopharynx primaries, the addition of concurrent chemotherapy to preoperative radiotherapy have significantly improved the PFS, DMFS, and even the OS with borderline significance $(P=0.054)$.

We have not observed a statistical difference in 5-year OS between the Pre-S CRT and Pre-S RT (53.8\%v

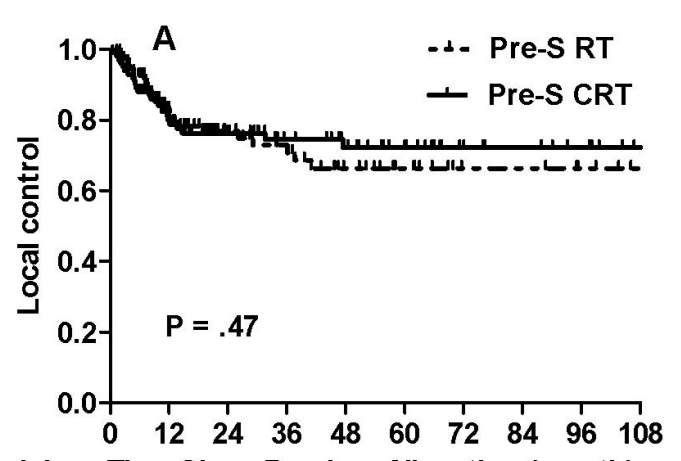

No at risk Time Since Random Allocation (month) $\begin{array}{llllllllllll}\text { Pre-S } & \text { RT } & 118 & 69 & 43 & 34 & 24 & 17 & 10 & 10 & 7 & 4\end{array}$ Pre-S CRT $104 \begin{array}{lllllllll}66 & 52 & 39 & 32 & 24 & 15 & 12 & 9 & 3\end{array}$

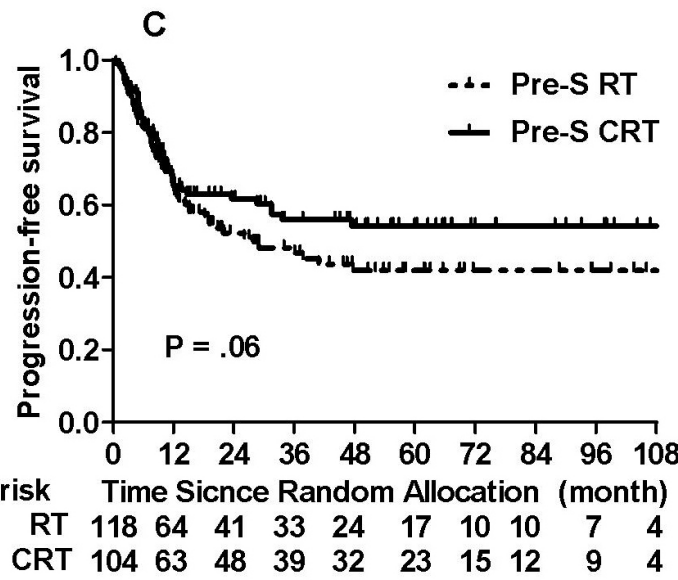

$39.0 \%, P=0.13$ ) in the entire group of non-nasopharynx HNSCC, however, the OS rates of these two groups are not different from results of the previous phase 3 trials of comparing definitive CRT versus definitive RT alone in the North America and Europe. For example, Adelstein et al [14] reported 5-year OS of 50\% for concurrent CRT group and $48 \%$ for RT alone group in patients with locally advanced HNSCC. Forastiere et al [22] reported the 5 -year OS were $56 \%$ for RT alone group and 54\% for concurrent CRT group (RTOG 91-11 trial). In addition, similar OS results were also reported in patients with locally advanced HNSCC treated with concurrent CRT versus induction chemotherapy followed by concurrent CRT. Lefebvre et al [23] reported no difference in 5-year OS between patients treated with induction chemotherapy followed by concurrent CRT with or without surgery versus patients treated with concurrent CRT with or without surgery in locally advanced larynx-hypopharynx carcinomas $(48.5 \%$ v 51.9\%, $P=0.446)$. Most recently, Lorch et al [24] reported significant improvement in 5 -year OS in patients treated with intensive neoadjuvant induction chemotherapy consisting of docetaxel, cisplatin and 5-flurouracial (TPF) followed by concurrent CRT compared with patients treated with induction

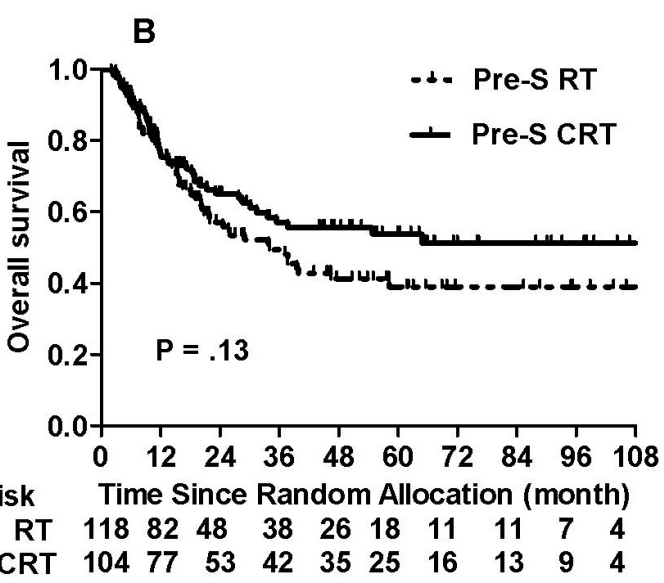

$\begin{array}{lccccccccccc}\text { Pre-S } & \text { RT } & 118 & 82 & 48 & 38 & 26 & 18 & 11 & 11 & 7 & 4 \\ \text { Pre-S } & \text { CRT } & 104 & 77 & 53 & 42 & 35 & 25 & 16 & 13 & 9 & 4\end{array}$

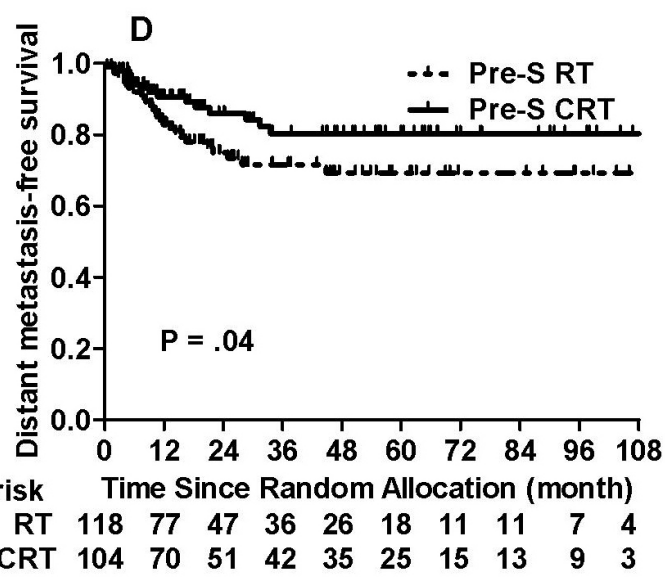

Figure 2: Comparison of the treatment outcomes between Pre-S RT and Pre-S CRT groups for whole cohort. 
chemotherapy consisting of cisplatin and 5-flurouracial (PF) followed concurrent chemoradiotherapy (52\% v 42\%, $P=0.014)$. It is noted that 5-year OS $(52 \%)$ in patients treated with induction TPF followed by concurrent chemoradiotherapy in that study is not different from OS (53.8\%) observed in the Pre-S CRT group of our study and the OS results of other previous phase III trials using definitive concurrent CRT [14, 22].

Currently three cycles of high-dose cisplatin $100 \mathrm{mg} / \mathrm{m}^{2}$ every three weeks are commonly used in combination with definitive radiotherapy of 70 Gy in 35 daily fractions in the treatment of locally advanced HNSCC in many institutions of the North America. However, this high-dose cisplatin regimen concurrent with definitive RT is reportedly very toxic, only $31 \%$ patients were able to complete the planed full-dose cisplatin [25]. Severe toxicities (grade 3 or more) of this high-dose cisplatin regimen concurrent with definitive RT of HNSCC were much higher compared with RT alone. Results from definitive concurrent CRT arm of three RTOG HNSCC trials (RTOG 91-11, 97-03, and 99-14) showed that 43\% patients had a severe late toxicity, and $10 \%$ patients died from treatment-related late toxicities. The factors

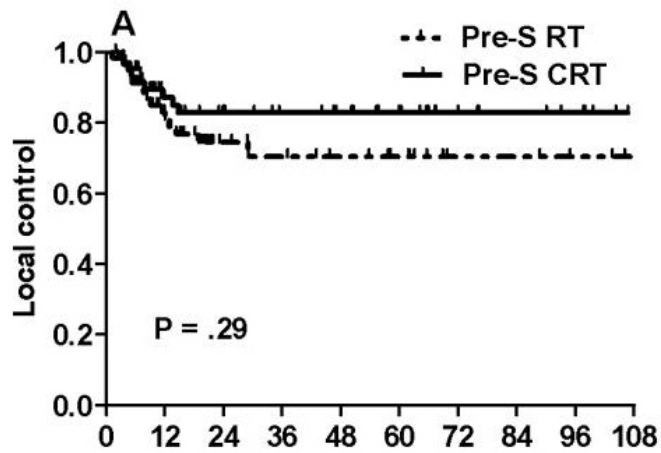

No at riks Time Since Random Allocation (month) $\begin{array}{llllllllllll}\text { Pre-S } & \text { RT } & 68 & 41 & 21 & 18 & 15 & 12 & 6 & 6 & 4 & 2\end{array}$ $\begin{array}{lllllllllll}\text { Pre-S CRT } & 60 & 40 & 31 & 27 & 25 & 17 & 10 & 8 & 6 & 2\end{array}$

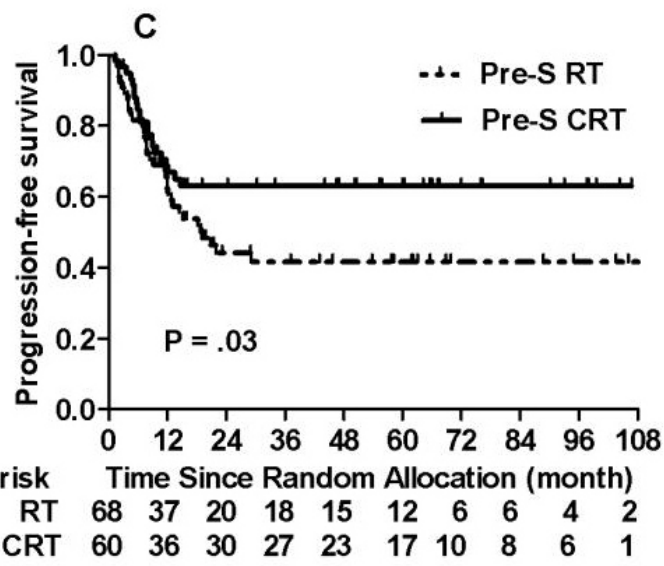

associated with these severe late toxicities include old age, advanced T-stage, and larynx-hypopharynx primaries, neck dissection after definitive CRT [26]. Considering the poor tolerance of Chinese patients, increased percentage of patients with larynx-hypopharynx primaries, and common use of planned dissection for patients with N2/3, we chose this weekly $30 \mathrm{mg} / \mathrm{m}^{2}$ cisplatin regimen concurrent with preoperative RT. Results of this study indeed show that this is well tolerated CRT regimen, most of toxicities were grade 1 and grade 2 , with only $16.3 \%$ of grade $3+$ hematology toxicities observed in Pre-S CRT group (Table 2). We did not observe difference in non-hematologic toxicities between these two groups. More recently, this weekly cisplatin regimen $\left(30-40 \mathrm{mg} / \mathrm{m}^{2}\right)$ concurrent with RT was chosen to treat Asian patients with locally advanced HNSCC [27].

There are several possible reasons to explain why addition of weekly Cisplatin concurrent to preoperative RT failed to provide benefits in overall survival. One pitfall might be that a mixed population of patients with HNSCC including oral cavity, oropharynx and larynxhypopharynx primaries was enrolled to this study. Tumor biology and aggressiveness of the above subsites might

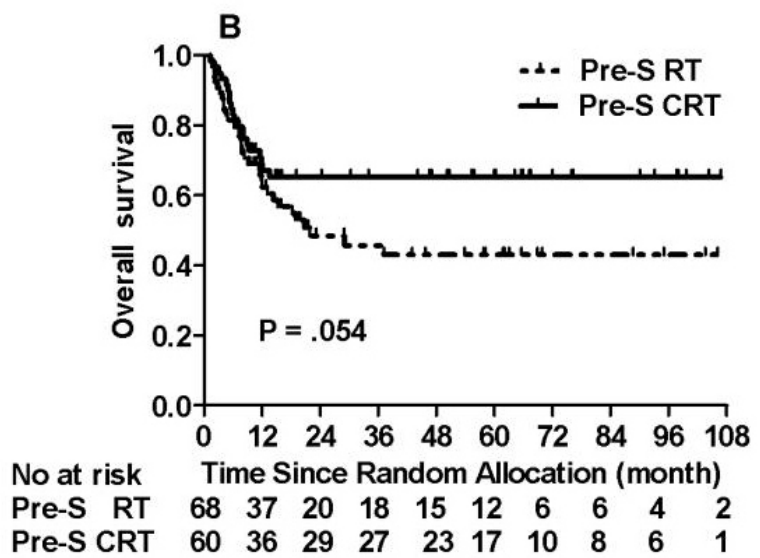

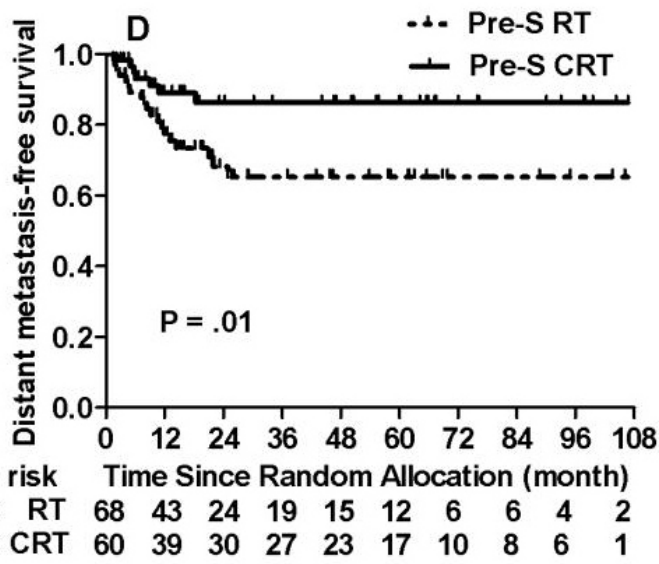

Figure 3: Comparison of the treatment outcomes between Pre-S RT and Pre-S CRT groups ristricted to primary larynx-hypopharynx carcinoma only. 
be different event though their squamous cell cancer histology is the same. Our subset analyses of patients with larynx-hypopharynx primaries indeed demonstrated that the addition of weekly cisplatin to preoperative RT has significantly improved PFS, DMFS, and also borderline OS (might be secondary to a limited sample size of larynxhypopharynx primaries enrolled to this study). Another observation is that a high percentage $(57.7 \%)$ of larynxhypopharynx primaries was recruited to this study. This is significantly different from previous studies in North America and Europe where oropharynx primary was dominant. This might translate to a significant difference in tumor biology and treatment response to CRT or RT. For example, HPV is prevalent in oropharynx primary in North America and Europe and the HPV positive oropharynx cancer is known to be highly sensitive to CRT or RT. The HPV positive oropharynx cancer patients had much better overall survival compared with the HPV negative HNSCC [28]. Chemotherapy might not even be required for oropharynx cancer with favorable risk factors [29, 30].

For locally advanced larynx-hypopharynx primaries, larynx function preservation is another objective goal. Results of the subset analyses showed the laryngectomyfree survival in the Pre-S CRT is higher than that in the Pre-S RT group, $75.5 \%$ v $64.5 \%$, but without statistical significance $(P=0.23)$. However, this result is not significantly different from literature reports, for example, Lefebvre et al [23] reported 3-year and 5-year estimates of retaining a functional larynx in patients treated in the induction-chemotherapy arm were $39.5 \%$ and $30.5 \%$. Pointreau et al [31] reported a the 3-year actuarial larynx preservation rate was $70.3 \%$ with TPF vs $57.5 \%$ with PF chemotherapy $(P=0.03)$ in patients with resectable larynx- hypopharynx primaries.

In summary, the addition of weekly cisplatin concurrent to preoperative RT has not provided overall survival benefit in the treatment of locally advanced non-nasopharynx HNSCC (a mixed population of oral cavity, oropharynx, hypopharynx and larynx) in this study, however, results from the subset analysis of larynxhypopharynx primaries dominant in this study (57.7\%) suggest the addition of weekly cisplatin has provided significant benefits in progression-free survival, distant metastasis free survival, and borderline benefit in overall survival, along with acceptable toxicity profile, compared with preoperative RT alone.

\section{MATERIALS AND METHODS}

\section{Eligibility criteria}

Adult patients with resectable, histologically proven squamous cell carcinoma of oropharynx, hypopharynx, oral cavity and larynx, stage III to IVB according to the 2002 UICC/AJCC staging system, Karnofsky performance status score $\geq 70$, adequate hematologic (leukocyte count $>4,000 / \mathrm{mm}^{3}$ and platelet count $>100,000 / \mathrm{mm}^{3}$ ), normal renal function (serum creatinine level $>1.5 \mathrm{mg}$ / $\mathrm{dL}$ ), and normal hepatic function were eligible for this study. Exclusion criteria include a previous history of chemotherapy or radiotherapy, any other cancer diagnosis within 5 years and severe comorbidities that contraindicated the use of chemotherapy or radiotherapy.

All patients had history and physical examination including the dedicated head and neck examination, and endoscopy evaluation of upper aero-digest tract, CT and/ or MRI of neck, chest X-ray, CT scan or ultrasonic of abdomen and pelvis before the registration.

\section{Random assignment and treatment}

This is an open-labeled randomized phase 3 trial approved by our institution human study board. Each eligible patient first signed informed consent, were then registered and randomly assigned to receive either preoperative concurrent chemoradiotherapy (Pre-S CRT group), or preoperative radiotherapy (Pre-S RT group). One stratification factor was primary disease site (larynx-hypopharynx v. other). The detailed study design information was shown in Figure 1.

For patients assigned to the CRT group, cisplatin of $30 \mathrm{mg} / \mathrm{m}^{2}$ once per week was delivered at the first day of radiotherapy. The initial radiotherapy regimen in both arms was identical, preoperative dose of 50 Gy in 25 daily fractions prescribed to the primary tumor and nodal disease. The radiotherapy technique was either conventional radiotherapy or recently intensity-modulated radiotherapy (IMRT) using $6 \mathrm{MV}$ photons.

\section{Assessment of tumor response and surgery decision making}

The tumor response was assessed at the end of $5^{\text {th }}$ week (50 Gy) by CT and/or MRI and endoscopy examination. All cases were then discussed in our weekly multidisciplinary head and neck oncology board. Responders ( $\geq 80 \%$ reduction of primary lesion) received a boost to primary gross tumor volume up to a total dose of 70 Gy in 35 daily fractions in Pre-S RT group or in combination with concurrent weekly cisplatin (Pre-S CRT). A modified neck dissection was planned for all patients with N2/3 within 6-8 weeks after the completion of $70 \mathrm{~Gy}$. Non-responders ( $<80 \%$ reduction of primary lesion) underwent resection of primary tumor and modified neck dissection in 4-6 weeks after the completion of preoperative 50 Gy in Pre S RT group or in combination with concurrent weekly cisplatin in Pre S CRT group. 


\section{Follow-up and statistics analysis}

The first follow-up visit was done at 1 month after the completion of protocol treatment, and then every 3 month for the first 2 years, every 6 month for the 3-5 years, and then once a year.

The primary endpoint of this study was overall survival (OS), defined as the time to death as a result of any cause. Assuming that the 5-year OS in the Pre-S RT group was $40 \%$ and $55 \%$ in the Pre-S CRT group, with a two-sided log-rank test at a level of significance of 0.05 and $80 \%$ power to detect the differences, with an estimated rate of early dropout or loss to follow-up of $20 \%$, the target accrual sample size was 210 patients.

Secondary endpoints included locoregional control (LRC), progression-free survival, distant metastasisfree survival and laryngectomy-free survival for larynxhypopharynx primary. All events were measured from the date of registration and the analyses were performed on an actual-to-treat basis to compare the treatment outcomes between these two groups.

\section{CONFLICT OF INTEREST}

All authors have no conflict of interest to declare.

\section{FUNDING}

This study was partly supported by the National Natural Science Foundation of China (81172125) and Beijing Hope Run Special Fund of Cancer Foundation of China LC2014L12 and The National Key Projects of Research and Development of China (2016YFC0904600) .

Preliminary results presented as oral presentation at the 53th Annual Meeting of the American Society of Radiation Oncology (ASTRO), Miami, FL, Oct2-6, 2011. Clinical trial information: ChiCTRTRC-114004322.

\section{Authors' contributions}

$\mathrm{Xu}$

Conception and design: Junlin Yi, Li Gao, Zhengang

Administrative support: Li Gao

Provision of study materials or patients: Junlin Yi, Xiaodong Huang, Zhengang $\mathrm{Xu}$, Shaoyan Liu, Xiaolei Wang, Xiaohui He, Dehong Luo, Jingwei Luo, Jianping Xiao, Shiping Zhang, Kai Wang, Yuan Qu, Yuan Tang, Weixin Liu, Guozhen Xu, Li Gao, Dian Wang

Collection and assembly of data: Junlin Yi, Xiaodong Huang, Shaoyan Liu, Yuan Tang, Weixin Liu, Li Gao, Dian Wang Dian Wang
Manuscript writing: Junlin Yi, Li Gao, Dian Wang Final approval of manuscript: All authors

\section{REFERENCES}

1. Kramer S, Gelber RD, Snow JB, Marcial VA, Lowry LD, Davis LW and Chandler R. Combined radiation therapy and surgery in the management of advanced head and neck cancer: final report of study 73-03 of the Radiation Therapy Oncology Group. Head Neck Surg. 1987; 10:19-30.

2. Tupchong L, Scott CB, Blitzer PH, Marcial VA, Lowry LD, Jacobs JR, Stetz J, Davis LW, Snow JB, Chandler R. Randomized study of preoperative versus postoperative radiation therapy in advanced head and neck carcinoma: long-term follow-up of RTOG study 73-03. Int J Radiat Oncol Biol Phys. 1991; 20:21-28.

3. Vandenbrouck C, Sancho H, Le Fur R, Richard JM, Cachin Y. Results of a randomized clinical trial of preoperative irradiation versus postoperative in treatment of tumors of the hypopharynx. Cancer. 1977; 39:1445-449.

4. Tang PZ, Tu GY. sugery modality and multidisciplinary treatment for hypopharyngeal carcinoma. Chin J otorhinolaryngol. 1992; 27:17-19.

5. Xiao GL, Gao L, Xu GZ. Treatment for hypopharyngeal carcinoma. Chin J Radiat Oncol. 2002; 11: 7-10.

6. Xiao GL, Xu GZ, Gao L, Li SY, Xiao JP. Value of preoperative radiotherapy in laryngeal functional preservation in pyriform sinus cacinoma. Chin J Oncol. 2001; 10: 100103.

7. Zhang B, Tang PZ, Xu GZ, Cai WM, Hu YH. Supraglottic carcinoma:does preoperative radiotherapy reduce the incidence of cervical metastasis? Chin Med J. 1998; 8: 3337.

8. Zhang B, Tang PZ, Xu GZ, Cai WM, Li QH, Qi YF, Yin YL. Preoperative radiotherapy for supraglottic with clinical positive cervical lymphadenophathy- A radonmized study. Chin Arch Otolaryngol Head Neck Surg. 1995; 2:90-93.

9. Zhang ZM, Tang PZ, Xu ZG, Li QH, Hu YH. Long term results of different treatment modalities in 464 hypopharyngeal squamous-cell carcinoma patients. Chin J Oncol. 2005; 27:48-53.

10. Zhang ZM, Tang PZ, Xu ZG, Qi YF. Significance of different preoperative radiation dose in combine therapy for hypopharyngeal squamous cell carcinoma. Chin J Radiat Oncol. 2004; 13:1-3.

11. del Campo JM, Felip E, Giralt J, Raspall G, Bescos S, Casado S, Maldonado X. Preoperative simultaneous chemoradiotherapy in locally advanced cancer of the oral cavity and oropharynx. Am J Clin Oncol. 1997; 20:97-100.

12. Giralt JL, Gonzalez J, del Campo JM, Maldonado J, Sanz X, Pamias J, Eraso A, Bescos S, Raspall G. Preoperative induction chemotherapy followed by concurrent chemoradiotherapy in advanced carcinoma of the oral cavity and oropharynx. Cancer. 2000; 89:939-945. 
13. Kirita T, Ohgi K, Tsuyuki M, Kamikaido N, Yamamoto K, Sugimura M. Preoperative simultaneous cisplatin- or carboplatin-based chemotherapy and radiotherapy for squamous cell carcinoma of the oral cavity. J Surg Oncol. 1996; 63: 240-248.

14. Adelstein DJ, Lavertu P, Saxton JP, Secic M, Wood BG, Wanamaker JR, Eliachar I, Strome M, Larto MA. Mature results of a phase III randomized trial comparing concurrent chemoradiotherapy with radiation therapy alone in patients with stage III and IV squamous cell carcinoma of the head and neck. Cancer. 2000; 88:876-883.

15. Adelstein DJ, Li Y, Adams GL, Wagner H Jr, Kish JA, Ensley JF, Schuller DE, Forastiere AA. An intergroup phase III comparison of standard radiation therapy and two schedules of concurrent chemoradiotherapy in patients with unresectable squamous cell head and neck cancer. J Clin Oncol. 2003; 21: 92-98.

16. Adelstein DJ, Saxton JP, Lavertu P, Tuason L, Wood BG, Wanamaker JR, Eliachar I, Strome M, Van Kirk MA. A phase III randomized trial comparing concurrent chemotherapy and radiotherapy with radiotherapy alone in resectable stage III and IV squamous cell head and neck cancer: preliminary results. Head Neck. 1997; 19: 567-575.

17. Jacobs C, Lyman G, Velez-Garcia E, Sridhar KS, Knight W, Hochster H, Goodnough LT, Mortimer JE, Einhorn LH, Schacter L. A phase III randomized study comparing cisplatin and fluorouracil as single agents and in combination for advanced squamous cell carcinoma of the head and neck. J Clin Oncol. 1992; 10:257-263.

18. Jeremic B, Shibamoto Y, Stanisavljevic B, Milojevic L, Milicic B, Nikolic N. Radiation therapy alone or with concurrent low-dose daily either cisplatin or carboplatin in locally advanced unresectable squamous cell carcinoma of the head and neck: a prospective randomized trial. Radiother Oncol. 1997; 43:29-37.

19. Pignon JP, Bourhis J, Domenge C, Designe L. Chemotherapy added to locoregional treatment for head and neck squamous-cell carcinoma: three meta-analyses of updated individual data. MACH-NC Collaborative Group. Meta-Analysis of Chemotherapy on Head and Neck Cancer. Lancet. 2000; 355:949-955.

20. Forastiere AA, Zhang Q, Weber RS, Maor MH, Goepfert H, Pajak TF, Morrison W, Glisson B, Trotti A, Ridge JA, Thorstad W, Wagner H, Ensley JF, et al. LongTerm Results of RTOG 91-11: A Comparison of Three Nonsurgical Treatment Strategies to Preserve the Larynx in Patients With Locally Advanced Larynx Cancer. J Clin Oncol. 2013; 31: 845-852.

21. Pignon JP, le Maitre A, Maillard E, Bourhis J. Metaanalysis of chemotherapy in head and neck cancer (MACHNC): an update on 93 randomised trials and 17,346 patients. Radiother Oncol. 2009; 92:4-14.

22. Forastiere AA, Goepfert H, Maor M, Pajak TF, Weber R, Morrison W, Glisson B, Trotti A, Ridge JA, Chao C, Peters G, Lee DJ, Leaf A, et al. Concurrent chemotherapy and radiotherapy for organ preservation in advanced laryngeal cancer. N Engl J Med. 2003; 349:2091-2098.

23. Lefebvre JL, Rolland F, Tesselaar M, Bardet E, Leemans CR, Geoffrois L, Hupperets P, Barzan L, de Raucourt D, Chevalier D, Licitra L, Lunghi F, Stupp R, et al. Phase 3 randomized trial on larynx preservation comparing sequential $\mathrm{v}$ alternating chemotherapy and radiotherapy. $\mathrm{J}$ Natl Cancer Inst. 2009; 101:142-152.

24. Lorch JH, Goloubeva O, Haddad RI, Cullen K, Sarlis N, Tishler R, Tan M, Fasciano J, Sammartino DE, Posner MR. Induction chemotherapy with cisplatin and fluorouracil alone or in combination with docetaxel in locally advanced squamous-cell cancer of the head and neck: long-term results of the TAX 324 randomised phase 3 trial. Lancet Oncol. 2011;12:153-159.

25. Granata R, Pond G, Kim J, Siu LL. Cisplatin dose intensity correlates with outcome in patients with locally advanced head and neck squamous cell carcinoma receiving concurrent cisplatin based chemoradiation: a multiinstitutional experience. Eur J Cancer. 2009; 7: 472.

26. Machtay M, Moughan J, Trotti A, Garden AS, Weber RS, Cooper JS, Forastiere A, Ang KK. Factors associated with severe late toxicity after concurrent chemoradiation for locally advanced head and neck cancer: an RTOG analysis. J Clin Oncol. 2008; 26:3582-3589.

27. D'Cruz A, Lin T, Anand AK, Atmakusuma D, Calaguas MJ, Chitapanarux I, Cho BC, Goh BC, Guo Y, Hsieh WS, Hu C, Kwong D, Lin JC, et al. Consensus recommendations for management of head and neck cancer in Asian countries: a review of international guidelines. Oral Oncol. 2013; 49:872-877.

28. Ang KK, Harris J, Wheeler R, Weber R, Rosenthal DI, Nguyen-Tân PF, Westra WH, Chung CH, Jordan RC, Lu C, Kim H, Axelrod R, Silverman CC, er al. Human papillomavirus and survival of patients with oropharyngeal cancer. N Engl J Med. 2010; 363:24-35.

29. Huang SH, Xu W, Waldron J, Siu L, Shen X, Tong L, Ringash J, Bayley A, Kim J, Hope A, Cho J, Giuliani M, Hansen A, et al. Refining American Joint Committee on Cancer/Union for International Cancer Control TNM stage and prognostic groups for human papillomavirus-related oropharyngeal carcinomas. J Clin Oncol. 2015; 33: 836845.

30. O'Sullivan B, Huang SH, Siu LL, Waldron J, Zhao H, Perez-Ordonez B, Weinreb I, Kim J, Ringash J, Bayley A, Dawson LA, Hope A, Cho J, et al. Deintensification candidate subgroups in human papillomavirus-related oropharyngeal cancer according to minimal risk of distant metastasis. J Clin Oncol. 2013; 31:543-550.

31. Pointreau Y, Garaud P, Chapet S, Sire C, Tuchais C, Tortochaux J, Faivre S, Guerrif S, Alfonsi M, Calais G. Randomized trial of induction chemotherapy with cisplatin and 5-fluorouracil with or without docetaxel for larynx preservation. J Natl Cancer Inst. 2009; 101:498-506. 